\title{
Themes and Trends in Australian and New Zealand Tourism Research: A Social Network Analysis of Citations in Two Leading Journals (1994-2007)
}

\author{
Pierre Benckendorff \\ James Cook University, Australia
}

\begin{abstract}
Assessments and rankings of the contribution and influence of scholars, institutions and journals in tourism are becoming increasingly common. This article extends the existing literature by providing a finer grained understanding of key influences in tourism research. This study presents a bibliometric analysis of the tourism literature by examining papers authored by Australian and New Zealand researchers in Annals of Tourism Research and Tourism Management between 1994 and 2007. A general picture of the field is drawn by examining keywords, the most-cited authors and works, as well as co-citation patterns. The analysis is extended by the use of social network analysis to explore the links between keywords and influential works in the field. The article also addresses the conference theme by identifying emerging themes and influences. Results indicate that tourism research in Australia and New Zealand has been strongly influenced by sociology and anthropology, geography and behavioural psychology. Emerging themes have focused on the health and safety of tourists, risk, wine tourism and segmentation.
\end{abstract}

Keywords: bibliometrics, social network analysis, Australia, New Zealand, research, trends 
that the measurement of research contribution and productivity is necessary for benchmarking of tourism research against other disciplines. More importantly, the evaluation of research also provides evidence of changes in research contributions over time (Jogaratnam, Chon et al., 2005).

Tourism is a maturing field, with a considerable specialist literature, and relationships with traditional disciplines that are now fairly stable and well understood (Xiao \& Smith, 2006b). In a mature field, various forms of 'score-keeping' are undertaken to investigate the most productive and influential scholars, institutions and publications. As a result there has been renewed interest in assessing and ranking tourism journals based on both perceived quality and influence (Jamal, Smith, \& Watson, 2008; McKercher, Law, \& Lam, 2006; Pechlaner, Zehrer, Matzler, \& Abfalter, 2004; Ryan, 2005). This interest has extended to the ranking of individual academics and institutions based on publication and citation counts (Jogaratnam, Chon et al., 2005; Jogaratnam, McCleary, Mena, \& Yoo, 2005; McKercher, 2007, 2008; Zhao \& Ritchie, 2007). These recent attempts build on the earlier studies of Sheldon (1990, 1991). In addition, the Australian Business Deans Council (ABDC) has recently released a list that ranks journals in various areas of business, including tourism (Australian Business Deans Council, 2008). It seems likely Australian tourism academics who have published in high-ranking journals will be seen as producing 'quality' work.

These developments serve to focus attention on the need to develop a good understanding of the key contributions, themes and trends in tourism research. While this partly entails an understanding of the most influential publication outlets and scholars, it is possible to go beyond the ranking of authors and journals by developing a more complex picture of the tourism research knowledge domain. This includes a better understanding of the literature that has influenced tourism researchers, key themes of this research and the links between research themes.

The purpose of this article is to provide a window through which the knowledge domain of Australian and New Zealand tourism research can be examined. This is achieved by investigating the contributions of Australian and New Zealander researchers in two leading tourism journals, Annals of Tourism Research and Tourism Management from 1994 to 2007 . It is not the intent of this study to provide commentary on the quality of scholars and the institutions that employ them. Indeed, it must be noted at the outset that this study concurs with the views of Beed \& Beed (1996, p. 369), who observe that 'the correlation between influence and quality is uncertain'. Furthermore, this study does not pretend to present a definitive view of tourism research in Australia or New Zealand, but rather to add to the extant knowledge by applying several bibliometric techniques to elucidate the themes, trends and 'invisible colleges' of tourism research. The key research questions examined by this article include:

- What key themes can be discerned from the keywords of papers published by Australian and New Zealand authors?
- Which authors and publications have influenced tourism researchers in Australia and New Zealand?

- What are the co-citation networks among influential cited works in the field of tourism? What schools of thought are presented among co-citation networks?

Tourism research in Australia and New Zealand has grown dramatically over the past 15 years, with contributions from multiple disciplines and theoretical and methodological perspectives. By examining the most cited authors and papers, as well as co-citation patterns, a general representation of the field showing key influences and influencers can be developed.

The next section of this article provides a framework for understanding the techniques which can be used to understand a field of research. The technique of citation analysis is then examined and applied to explore the structure of tourism research in Australia and New Zealand. The article ends with a discussion of the results, a description of the evolution of the field, and an outline of the main conclusions and directions for future research.

\section{Techniques for Analysing Research Contributions}

There are a number of techniques for analysing research contributions, themes and trends in a particular field. These techniques range from qualitative (and often subjective) evaluations to objective quantitative measures of research contribution. Collectively most of the quantitative approaches form part of the field of bibliometrics, which encompasses the measurement of 'properties of documents, and of document-related processes' (Borgman \& Furner, 2002, p. 3). Advances in information technology, and improvements in the coverage of bibliometric databases such as ISI Web of Science (WoS), Scopus and Google Scholar (GS) have seen substantial advances in bibliometric analysis.

Generally speaking, the various techniques can also be categorised as either evaluative or relational (Borgman \& Furner, 2002; Thelwall, 2008). Evaluative techniques seek to assess the impact of scholarly work, usually to compare the relative scientific contributions of two or more individuals or groups. The ranking or rating of publication outlets, authors or institutions are examples of this type of research. These evaluations have become increasingly common in tourism. In contrast, relational techniques seek to illuminate relationships within research, such as the structure of research fields, the emergence of new research themes and methods, or national and international co-authorship patterns.

Table 1 provides a summary of the range of techniques using this typology, along with an indication of researchers in tourism and the related field of hospitality who have used these techniques. Many of these authors have used multiple complementary approaches. These techniques are briefly discussed below.

Qualitative evaluative techniques involve members of a particular academic community ranking journals (or scholars) on the basis of their own expert judgements. They are often subjective in nature because they rely on expert panels or peer review to generate data. A seminal 
study by Sheldon (1990) used a peer evaluation approach to determine the leading journals in tourism and hospitality and has been replicated by a number of authors. Expert panels represent a variation of the peer evaluation method and usually involve the use of an exclusive or predetermined sample of respondents who are regarded as 'experts' in the field. Expert panels have been used in a number of fields to rank journals and authors and are used widely by institutions and governments (McKercher et al., 2006).

There are a range of quantitative evaluative techniques for assessing the contribution of institutions, journals and authors to a discipline or field. These techniques are based on actual publication behaviour and include rankings based on simple counts of the number of papers published in selected journals or evaluations of the number of citations received by authors. A slightly different approach has involved using web-site statistics to count the number of hits particular papers have attracted, but this is not without its limitations (Ryan, 2005). Citation counts form the basis for the calculation of indices such as impact factors, $h$-index and $g$-index which aim to provide arithmetically robust indicators of research quality (Egghe, 2006; Hirsch, 2005). By analysing which authors and papers are cited frequently, citation rates and indices go beyond a simple counting of publications to an analysis of which authors and publications have value to other researchers (Pasadeos, Phelps, \& Kim, 1998). These are both the most common and most controversial approaches to measuring research contribution and productivity, chiefly because they have been used for crossdisciplinary comparisons.

Despite the common use of citation rates and indices in other disciplines, the data required for citation-based evaluative approaches are operationally difficult to prepare because of the considerable pragmatic challenges associated with constructing a dataset that is likely to be representative of the entire tourism knowledge domain (McKercher, 2008; Schmidgall et al., 2007). These problems are compounded by the fact that the tourism field has not historically been well served by citation databases like WoS. This means that it has often been difficult to calculate citation indices for scholars in the tourism field. Recent developments have introduced alternatives such as Elsevier's Scopus and Google Scholar, and this has created some pressure for these databases to become more inclusive. Scopus provides broader coverage of tourism titles, but the development of Google Scholar in 2004 has created further opportunities for tracking the contribution of tourism scholars based on these data (McKercher, 2008).

Given the variety of evaluative approaches, it is not surprising that there is considerable debate among the academic community about the merits and limitations of various techniques. This is not limited to tourism, but a number of discipline specific commentaries have been provided, most notably in the hospitality field and through various recent opinion pieces in Tourism Management (Hall, 2005; Jamal et al., 2008; Losekoot, Verginis, \& Wood, 2001; Page, 2005; Pearce, 1992; Wood, 1995). Many of these concerns centre on the consistency and validity of journal, institutional and individual rankings. There is particular criticism of the selection of the journals sampled, the timeframes used in sampling procedures, sample representativeness and various arithmetic procedures employed in calculating output measures. Page $(2005$, p. 665) has argued that the existence of league tables and rankings stymie creativity and are 'divisive, potentially demoralising and ... not in the interest of knowledge development'. McKercher et al. (2006, p. 1236) observe that ' $\ldots$ in spite of the best efforts to rate journals, no single, absolute, infallible method exists'. It is unlikely that the widespread use of evaluative techniques such as citation or publication rankings will diminish but the comments by McKercher et al. suggest that a variety of techniques are necessary for understanding a knowledge domain.

Qualitative relational techniques such as literature reviews, meta-analyses and content analyses are common in tourism and have been used to investigate key themes

Table 1

Techniques for Analysing Research Contributions

\begin{tabular}{|c|c|c|}
\hline & Evaluative & Relational \\
\hline \multirow[t]{4}{*}{ Subjective (Qualitative) } & \multirow{2}{*}{$\begin{array}{l}\text { Peer evaluation (Hsu \& Yeung, 2003; McKercher et al., 2006; } \\
\text { Pechlaner et al., 2004; Schmidgall, Woods, \& Hardigree, 2007; } \\
\text { Sheldon, 1990; Zehrer, 2007) }\end{array}$} & Literature reviews \\
\hline & & Conceptual mapping \\
\hline & \multirow[t]{2}{*}{ Expert panels (Ferreira, DeFranco, \& Rappole, 1994, 1998) } & $\begin{array}{l}\text { Content analysis (Baloglu \& Assante, 1999; Crawford-Welch \& } \\
\text { McCleary, 1992; Xiao \& Smith, 2005, 2006b) }\end{array}$ \\
\hline & & $\begin{array}{l}\text { Meta-analysis (Brey, Morrison, \& Mills, 2007; Dann, Nash, \& } \\
\text { Pearce, 1988; Palmer, Sesé, \& Montaño, 2005; Park \& Gretzel, } \\
\text { 2007; Reid \& Andereck, 1989; Shelby \& Vaske, 2008) }\end{array}$ \\
\hline \multirow[t]{6}{*}{ Objective (Quantitative) } & \multirow{2}{*}{$\begin{array}{l}\text { Publication counts (Jogaratnam, Chon et al., 2005; Jogaratnam, } \\
\text { McCleary et al., 2005; McKercher, 2007; Sheldon, 1991; Zhao \& } \\
\text { Ritchie, 2007) }\end{array}$} & $\begin{array}{l}\text { Co-word (title, keyword) analysis (Swain, Brent, \& Long, 1999; } \\
\text { Xiao \& Smith, 2006a) }\end{array}$ \\
\hline & & Co-author analysis \\
\hline & $\begin{array}{l}\text { Citation rankings, counts (Howey, Savage, Verbeeten, \& Van Hoof, } \\
\text { 1999; McKercher, 2008; Xiao \& Smith, 2005, 2006b) }\end{array}$ & Author citation analysis \\
\hline & Citation indices, impact factors (McKercher, 2008) & $\begin{array}{l}\text { Citation analysis (Barrios, Borrego, Vilagines, Olle, \& Somoza, 2008; } \\
\text { Howey et al., 1999; Samdahl \& Kelly, 1999) }\end{array}$ \\
\hline & Website hits (Ryan, 2005) & Co-citation analysis (Xiao \& Smith, 2008) \\
\hline & Journal acceptance rates & Social network analysis (Hu \& Racherla, 2008) \\
\hline
\end{tabular}


and trends and the evolution and statistical techniques and methodologies. Most frequently employed is the literature review where a highly subjective approach is used to report, structure and analyse earlier work. Meta-analyses can also be regarded as largely qualitative but tend to be more structured and systematic. The units of analysis have included paper titles, keywords, abstracts and statistical techniques. The key objective of this type of research usually involves tracking the evolution of tourism as a field of research. While there have been some criticisms of these studies and their conclusions (see, e.g., Hollinshead, 1991) they have generated far less controversy than the evaluative approaches discussed in this article.

The field of bibliometrics offers a range of more advanced quantitative relational techniques that extend the use of citation data beyond the simple evaluative counting and ranking of research productivity. One common technique involves the use of citations as a basis for further analysis. Citation analysis is based on the premise that heavily cited articles are seen as exerting a greater influence than those less frequently cited. Citation analysis is commonly conducted on a small sample of source journals that are well regarded within a discipline or field. In some cases analysis has been limited to a single influential journal, but more frequently two to four influential journals are analysed. Because the citations used in research papers form the basic unit of analysis, even a single journal can provide large, highly aggregated data sets for monitoring recurrent patterns, sometimes over relatively long time horizons (Leydesdorff, 1998). While the collection and analysis of detailed citation data have in the past posed the biggest challenge for this type of analysis, databases like WoS and Scopus have improved their coverage and are now much more accessible.

Co-citation analysis is an extension of citation analysis. While a list of the most cited authors can help indicate who is shaping the field and the most cited papers can illustrate key concepts that are driving a field, the addition of co-citation analysis to a bibliometric study adds insight into the evolution of a field of study. The basis of co-citation analysis is that pairs of documents that often appear together in reference lists (i.e., are co-cited) are likely to have something in common. A list of all possible pairs of works cited among all citations in a given document enables a researcher to obtain the basic data for co-citation frequencies and co-citation networks (Pasadeos et al., 1998). When two authors or papers are frequently cited together across a number of papers, there is a good likelihood that their ideas relate to each other. If collections of documents are arranged according to their co-citation counts then this should produce a pattern reflecting conceptual relationships. These relationships mean that the authors address the same issues, although it must be appreciated that this does not necessarily mean that they agree with each other. Schildt and Mattsson (2006) highlight that although some co-citations are unrelated, a sufficiently large sample of cited articles moderates the random 'noise' created by articles combining diverse topics or research traditions.
Co-citation analysis has proved to be a useful empirical technique for describing the intellectual structure of disciplines using an objective method. It has been applied in a range of other areas including internet advertising (Kim \& McMillan, 2008), family business research (Casillas \& Acedo, 2007), operations management (Pilkington \& Fitzgerald, 2006), services management (Pilkington \& Chai, 2008), strategic management (Acedo, Barroso, \& Galan, 2006), performance measurement (Neely, Gregory, \& Platts, 2005), and international management (Acedo \& Casillas, 2005). Figure 1 included several examples of citation and co-citation analyses conducted in tourism and hospitality.

Co-citation analysis has increasingly been used to construct a proximity matrix of interactions that can then be visualised using social network analysis (SNA). The strength of the tie between two works is calculated based on the number of articles that cite them both. Clustering algorithms can then be used to generate network diagrams, which typically indicate most influential sources and clusters that refer to schools of thought or 'invisible colleges'. The increasing use of sophisticated visualisations is an important development in relational bibliometrics and has led to the creation of a new field known as knowledge domain visualisation. The work of $\mathrm{Hu}$ and Racherla (2008) in the related field of hospitality provides a good recent example of this technique.

\section{Methodology}

This study provides a bibliometric analysis of tourism research in Australia and New Zealand by using papers published in Annals of Tourism Research (hereafter Annals) and Tourism Management between 1994 and 2007 as source data. The raw data were extracted from the ISI World of Science dataset. These two journals were selected for several reasons but represent a convenience sample, because they are the only tourism journals that have been included in WoS over a number of years. Somewhat fortuitously, these two journals are also prominent and influential publication outlets in the field of tourism, with a number of studies over the last 19 years consistently ranking these titles among the top three most influential journals (McKercher et al., 2006; Pechlaner et al., 2004; Ryan, 2005; Sheldon, 1990; Zehrer, 2007). Supplementary analysis was conducted in August 2008 using Google Scholar and the software package Publish or Perish to better understand the relative influence of these two tourism journals. A 'journal impact assessment' was conducted on ten tourism journals consistently ranked as leading journals by the researchers above. The timeframe was limited to papers published between 1994 and 2007. The assessment calculates two citation indices, the $h$ index and $g$-index for each journal based on the number of citations received. The citation indices confirm that for the period 1994-2007 Annals $(h$-index $=64 ; g$-index $=86$ ) and Tourism Management $(h$-index $=52 ; g$-index $=71$ ) were ranked first and second. They next highest score was received by fournal of Travel Research ( $h$-index $=45$; $g$ index $=63$ ). Since this study is concerned with tracking the most influential contributions to tourism research in 
Australia and New Zealand it makes sense to focus on the most influential international journals in the field. These journals are also 'mainstream' tourism journals with a broad treatment of topics and wide geographical coverage. The date limits for this study are set by WoS, which has incomplete records for Tourism Management papers published before 1994. The data for Annals extends back to 1982; however, in order to maintain some consistency with the Tourism Management dataset, only papers published in Annals after 1994 are included. Since this paper is concerned with analysing papers published by Australian and New Zealand authors only articles published by authors affiliated with institutions in these two countries at the time of publication were included. Following past studies of this type, the analysis does not include reviews, conference reports, editorials, notes, letters or errata.

A certain amount of manipulation was required to standardise entries and correct inconsistencies in the WoS data, particularly the spelling of author names, affiliations, and publication titles. These inconsistencies appear due to errors in the WoS data capturing process, variations in title abbreviations and discrepancies and errors made by authors themselves in the original papers. A common problem was that authors' names arbitrarily included one or two initials (e.g., P. Pearce, P.L. Pearce). There were also a number of obvious misspellings (e.g., Leiper, Lieper). Another problem encountered when examining citations was multiple editions of books. For the purpose of this study, books with multiple editions (e.g., Claire Gunn's Tourism Planning, 1972, 1988) have been recoded and treated as the same publication. The issues associated with affiliations were primarily caused by a change of name by some universities during the sample period (e.g., James Cook University, Charles Darwin University, Vic- toria University, Curtin University). The data cleaning exercise consumed about 6 hours and involved sorting the various fields alphabetically to more easily identify inconsistencies. The data were only amended when it was absolutely clear that there was an inconsistency that would affect the outcome of the analysis.

The data extracted from WoS included a total of 334 articles (135 from Annals and 199 from Tourism Management) by 389 different authors. The discrepancy is due to multiple articles by the same author and because many authors also feature as co-authors with others. Table 2 shows the authors and institutions with the most articles published in Annals and Tourism Management from 1994-2007. There are many Australian and New Zealand tourism researchers who publish excellent work in other publication outlets and this table should not be interpreted as a definitive ranking of influential tourism scholars and institutions. The information is provided to help readers understand the authorship structure of the raw dataset. It should be noted that some authors shown in Table 2 departed for postings in other countries during this timeframe (e.g., Stephen Page). These authors are included in the study. Likewise, the dataset includes a number of international authors who co-authored papers with Australian or New Zealand researchers. The paper counts for these authors, and subsequently their institutions, only include papers co-authored with researchers from Australia or New Zealand. Australian researchers authored or co-authored 252 papers while New Zealand authors were associated with 83 papers.

The 334 source articles produced a rich dataset of 11,629 citations, covering 9,278 works and drawing on 6,167 different lead authors. These works include a variety of references, including journal articles, books,

\section{Table 2}

Leading Contributors to Annals and Tourism Management, 1994-2007

\begin{tabular}{|c|c|c|c|c|c|}
\hline Author & Annals & TM & Institutions & Annals & TM \\
\hline Chris Ryan & 7 & 13 & Griffith University & 17 & 27 \\
\hline Bill Faulkner & 3 & 8 & University of Queensland & 7 & 14 \\
\hline Bruce Prideaux & 3 & 8 & University of Otago & 8 & 11 \\
\hline Stephen Page & 4 & 6 & University of Waikato & 5 & 12 \\
\hline Douglas Pearce & 4 & 4 & James Cook University & 6 & 9 \\
\hline David Simmons & 1 & 7 & La Trobe University & 4 & 11 \\
\hline Ralf Buckley & 6 & 1 & Lincoln University & 3 & 12 \\
\hline Brian King & 1 & 6 & Massey University & 4 & 11 \\
\hline Samuel Kim & 2 & 4 & Victoria University & 6 & 8 \\
\hline Rob Lawson & 4 & 2 & University Western Australia & 4 & 8 \\
\hline Michael McAleer & 2 & 4 & Monash University & 4 & 6 \\
\hline Bob McKercher & 3 & 3 & Southern Cross University & - & 9 \\
\hline Gordon Waitt & 5 & 1 & Australian National University & 6 & - \\
\hline Neil Carr & 1 & 4 & Hong Kong Polytechnic University & 2 & 4 \\
\hline Larry Dwyer & 2 & 3 & Sejong University & 2 & 4 \\
\hline Christine Lim & 3 & 2 & University of New South Wales & 2 & 4 \\
\hline Martin Oppermann & 2 & 3 & University of Stirling & 3 & 3 \\
\hline Mark Orams & - & 5 & University of Technology Sydney & 1 & 5 \\
\hline Philip Pearce & 3 & 2 & & & \\
\hline David Weaver & 3 & 2 & & & \\
\hline
\end{tabular}


conference papers, doctoral theses and reports. 1,254 of these works were cited more than once but many had very few co-citations and were either unlikely to have had a significant impact on the development of the field and/or were too recent to have had time to impact on the literature. As a matter of interest, the oldest cited work was Guillaume Rondelet's book, Libri de Piscibus Marinis (Book of Marine Fish) from 1554, followed by Niccolò di Bernardo dei Machiavelli's 1640 work The Prince. However, $96.6 \%$ of all citations were to works published after 1970 .

The data were further analysed using the Sitkis software package which has been purposely designed for conducting bibliometric analysis using WoS data (Schildt \& Mattsson, 2006). Sitkis allows researchers to conduct various bibliometric analyses on both the source articles and the citations themselves. For co-citation analysis the software uses a dense network subgrouping algorithm based on an iterative identification of tightly coupled areas to arrange citations into a matrix. This matrix can then be used to generate social network diagrams using the NetDraw software, which is included with the network analysis software suite UCINET (Borgatti, Everett, \& Freeman, 2008).

\section{Results}

Several analyses were conducted on the WoS dataset to address the research questions posed in the introduction of this article. The results are presented in two sections. The first section presents a network analysis of keywords found in the citing (source) papers for Australian and New Zealand Authors. The focus then shifts to a citation and co-citation analysis of cited references.

\section{Keyword Analysis}

The 334 papers in the dataset provided a list of 1,057 unique keywords which were examined as a means of determining the dominant themes in Australian and New Zealand tourism research. Of these, 44 keywords appeared more than five times. Table 3 shows a list of keywords appearing 10 or more times in the dataset.

In keeping with the theme of this conference, the analysis is broken down into two time periods of 7 years each to enable readers to identify important changes in the focus of Australian and New Zealand tourism research. Table 4 provides a summary of keywords that have shown the biggest positive or negative changes.

As might be expected, keywords like tourism, Australia and New Zealand rated highly in this particular dataset. However, the next tier of keywords represent a pre-occupation with research that is rooted in the disciplines of sociology and psychology. The attitudes, perceptions and motivations of visitors appear to be a key theme, particularly in the relation to authenticity and visitor experiences. Not surprisingly ecotourism and impacts also feature in the list of most common words and this represents a second theme. There is a third theme that appears to revolve around risk management. When looking at Table 4 it is clear that the interest in risk has increased dramatically between 2001 and 2007. Other notable emerging key-
Table 3

Most Common Keywords in Annals and Tourism Management Papers 1994-2007

\begin{tabular}{lccc}
\hline Keyword & 1994-2000 & 2001-2007 & Total \\
\hline Tourism & 31 & 26 & 57 \\
Australia & 11 & 12 & 23 \\
Behavior & 9 & 14 & 23 \\
New Zealand & 9 & 14 & 23 \\
Attitudes & 8 & 11 & 19 \\
Authenticity & 7 & 11 & 18 \\
Experience & 8 & 9 & 17 \\
Heritage & 8 & 9 & 17 \\
Ecotourism & 7 & 9 & 16 \\
Motivation & 8 & 8 & 16 \\
Perceptions & 8 & 7 & 15 \\
Sustainability & 5 & 10 & 15 \\
Culture & 7 & 7 & 14 \\
Impacts & 7 & 7 & 14 \\
Management & 3 & 9 & 12 \\
Risk & 0 & 10 & 10 \\
\hline
\end{tabular}

words include segmentation, Internet and volatility. The patterns associated with the keywords which have shown the most decline are less clear. The differences between 1994-2000 and 2001-2007 are not as marked and the key theme centres on tourism planning. It may be the case that authors are using these more generic terms less often in favour of more specific keywords.

It is possible to further explore the relationships between keywords by constructing a network based on how often pairs of keywords appear together in the same paper. This provides a tapestry of themes for discussion. Figure 1 provides a network diagram of keywords used in five or more papers. The size of the node provides a relative indication of the number of times each keyword was mentioned. The width of the links represents the number of times each pair of keywords were mentioned together

Table 4

Trends in Keywords from Annals and Tourism Management Papers 1994-2007

\begin{tabular}{lccc}
\hline Keyword & 1994-2000 & 2001-2007 & Change \\
\hline Risk & 0 & 10 & 10 \\
Wine tourism & 0 & 9 & 9 \\
Segmentation & 0 & 7 & 7 \\
Impacts & 7 & 13 & 6 \\
Management & 3 & 9 & 6 \\
Behavior & 9 & 14 & 5 \\
Internet & 0 & 5 & 5 \\
New Zealand & 9 & 14 & 5 \\
Sustainability & 5 & 10 & 5 \\
Volatility & 0 & 5 & 5 \\
\hline Planning & 4 & 0 & -4 \\
Leisure & 6 & 1 & -5 \\
Tourism & 31 & 0 & -5 \\
Tourism planning & 5 & -5 & \\
\hline
\end{tabular}




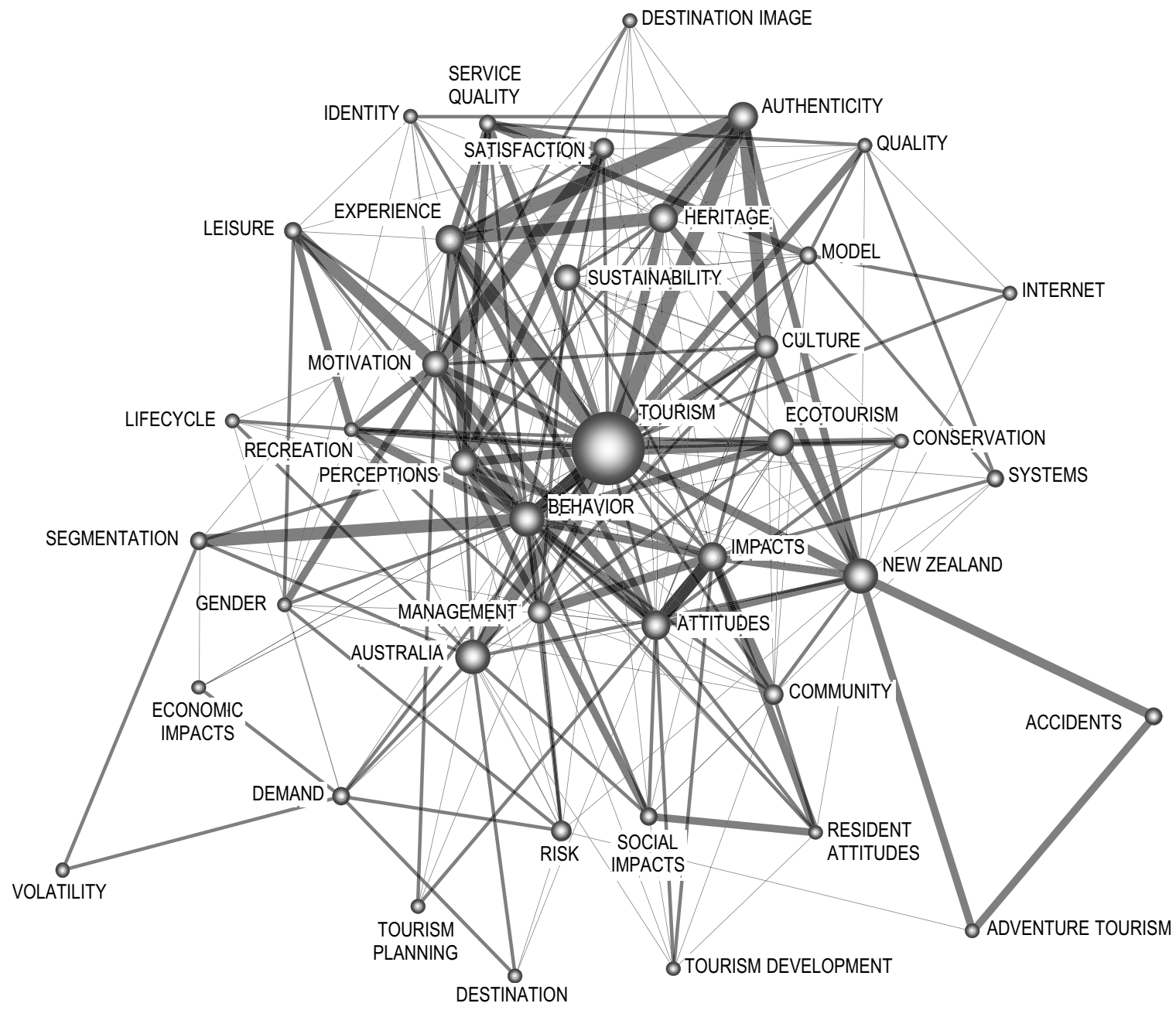

Figure 1

Network of keywords listed for papers in Annals and Tourism Management.

in the same paper. Isolates have been removed from the network to aid interpretation. A clustering algorithm is used to place the keywords on the network and the proximity of keywords to one another is therefore noteworthy. Not surprisingly 'tourism' is at the core of the matrix, with other common keywords listed in Table 3 close to the centre and less common keywords located towards the periphery.

The network analysis indicates that a number of keywords associated with understanding tourists are located close to the centre of the network. Concepts that deal with destinations, impacts and residents are located towards the periphery. The network confirms a number of strong links between keywords that reinforce the themes already discussed above. There strongest pairing is between authenticity and heritage (eight pairs). The links between tourism, authenticity and experience are also particularly strong. Likewise, there is a strong connection between motivation and satisfaction. The behaviour node is linked more strongly with perception and segmentation and to a lesser extent with motivation and attitudes. The research linked with Australia appears quite fragmented, but several keywords are linked to this node rather than the New Zealand node. In particular, large nodes such as sustainability, heritage and management are not linked with New Zealand. Towards the periphery of the network, the emerging work on segmentation, demand, volatility and lifecycles is more closely linked with papers that use Australia as a keyword. In New Zealand, there is a strong theme associated with accidents and adventure travel.

In network analysis those keywords on the periphery might be considered as important research fronts, or emerging areas. Large nodes towards the centre of the network are more likely to represent important research paradigms. Indeed, a number of the emerging keywords identified in Table 4 are found around the periphery. The accidents/adventure tourism theme appears to be an important emerging research front in New Zealand, but strangely risk is not strongly connected to these keywords. Risk is an important developing node and there are many linkages between this keyword and a number of other 
terms, suggesting that there are multiple dimensions to this research theme.

If the network is conceptualised as a compass, it is possible to identify in the Southeast a cluster of topics that deal with social impacts, communities and resident attitudes. This cluster appears to be concerned with social impacts of tourism. To the South the network appears to be focus more on planning and development issues and in the Southwest the focus is on economics and demand. The destination node is located in between the economic and social impact clusters. The Western side of the network appears to have a clear marketing focus while the North/Northwest is concerned with related issues of service quality and satisfaction. Moving around the network towards the East, issues of heritage and authenticity become more prominent, while ecotourism and conservation can be found directly East.

\section{Citation Analysis}

The analysis now moves away from the source documents to examine the characteristics of the citations provided in the reference list for each paper. This analysis draws on a sample of over 11,000 citations found in the reference lists of the 334 Australian and New Zealand papers in the sample. The spread of publications from which citations appeared is interesting. In total, the citations were drawn from 5,252 different publications, illustrating the diversity of work that influences the tourism field. The 10 most frequently cited journals are summarised in Table 5. Together these top 10 journals accounted for some $20.5 \%$ of citations. It can be argued that these 10 journals have had the most influence on tourism research in Australia and New Zealand.

To add another dimension to these data the $h$-index and $g$-index for each journal was calculated using Google Scholar and the Publish or Perish software package. It should be noted that this supplementary analysis considers all citations to all papers published in these journals between 1994 and 2007. It is interesting to note that there is a strong correlation between the number of citations and the citation indices from Google Scholar for the four most commonly cited journals. The fournal of Tourism
Studies breaks this pattern. This may be because this journal was the first Australian-based tourism journal.

It is possible to use the publication year for each citation to examine how many citations a journal receives for all of the papers published in a particular year. This provides an indication of how influential particular volumes of a journal are over time. Figure 2 provides a stacked area chart indicating the relative percentage of citations from the 10 most frequently cited journals according to the year of citation.

The most discernable trend from Figure 2 is the increasing numbers of recent citations to papers in Tourism Management at the expense of other journals, including Annals. This may be associated with an increase in the number of articles and issues being published in this journal. All things being equal, the more articles and issues are published, the more citations a journal can expect to receive. Tourism Management also provides online access to in press articles, which may allow authors to cite these papers before they have been officially published, thereby increasing the proportion of recent citations.

At a more detailed level, it is possible to explore the frequency of citations for individual authors and pieces of work. Table 6 provides a list of the top 25 authors most often cited by Australian and New Zealand researchers in Annals and Tourism Management. It is important to remember that WoS only records the first author in its citation database. However, if it is assumed that the first author normally makes the most substantial contribution to a paper then this list should provide a reasonably good approximation of the authors who have been the most influential sources for Australian and New Zealand tourism researchers.

The list of authors contains a number of prominent international scholars in the tourism field, but also has a strong Australian/New Zealand flavour. The far right column of the table provides a comparison with the most recent international ranking of tourism scholars undertaken by McKercher (2008). McKercher's ranking used a different methodology to previous papers because it was based on citation data collected from Google Scholar. Many of the most cited authors in this study are also included in McKercher's list, although there are notable exceptions.

\section{Table 5}

Most Frequently Cited Journals in Annals and Tourism Management, 1994-2007

\begin{tabular}{|c|c|c|c|}
\hline Publication & Citations & GS $h$-index & GS g-index \\
\hline Annals of Tourism Research & 1013 & 64 & 86 \\
\hline Tourism Management & 487 & 52 & 71 \\
\hline Journal of Travel Research & 417 & 45 & 63 \\
\hline Journal of Leisure Research & 94 & 33 & 46 \\
\hline Journal of Tourism Studies & 91 & 16 & 28 \\
\hline Journal of Sustainable Tourism & 82 & 26 & 36 \\
\hline Journal of Travel \& Tourism Marketing & 69 & 20 & 27 \\
\hline Journal of Marketing & 52 & 110 & 213 \\
\hline Cornell HRA Quarterly & 48 & 31 & 47 \\
\hline Journal of Marketing Research & 47 & 90 & 134 \\
\hline
\end{tabular}




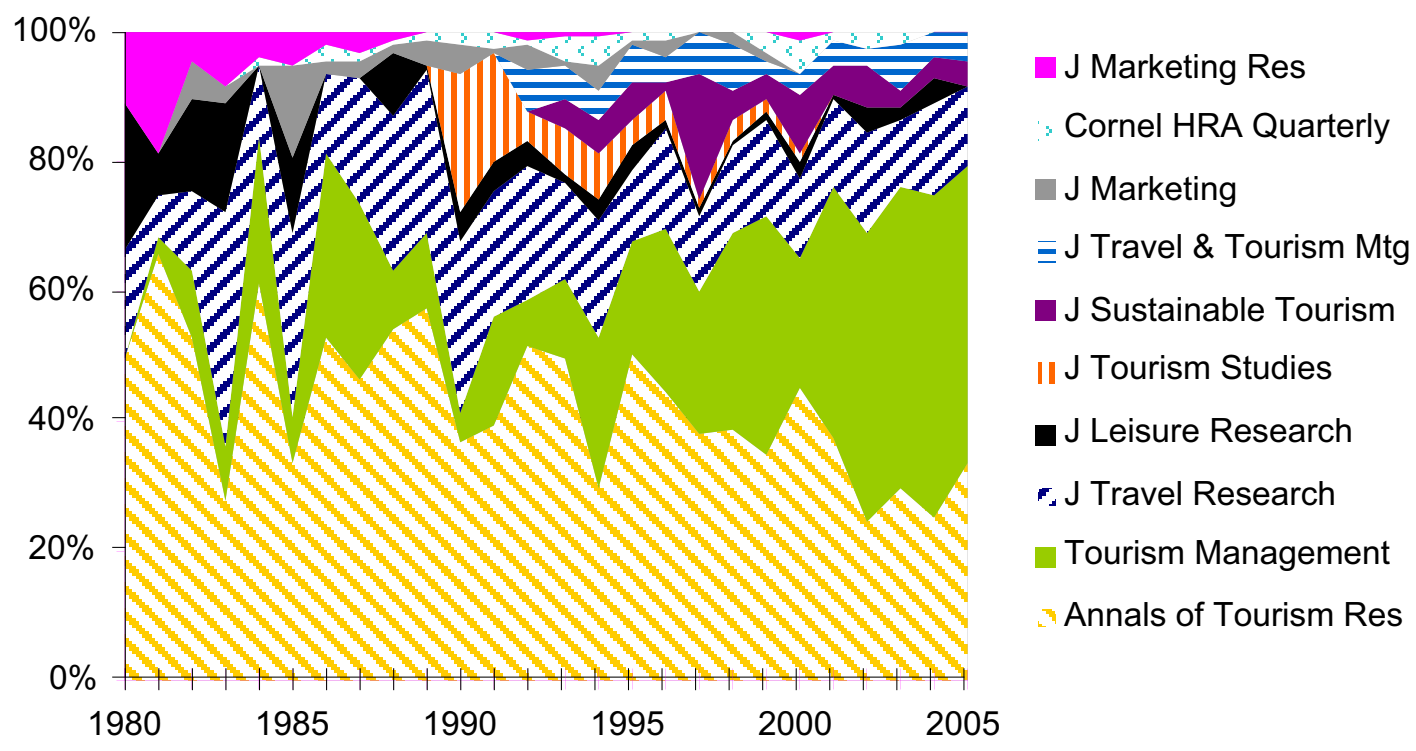

Figure 2

Top 10 most frequently cited journals by year of citation (1980-2005).

The table provides a summary of citations over two 7year periods to more easily discern key trends. The percentage of citations from 2001 to 2007 provides an indication of the level of influence various authors have enjoyed in the most recent 7 -year period. A percentage higher than $50 \%$ indicates authors who have become more influential through citations, while a percentage lower than $50 \%$ indicates authors who have been less influential. Authors who have shown a strong increase in citations and therefore have become more influential include Bruce Prideaux, Yvette Reisinger, Bill Faulkner, Stephen Page, Larry Dwyer, Mark Orams and Abraham

\section{Table 6}

Top 25 Most Cited Authors in Annals and Tourism Management, 1994-2007

\begin{tabular}{|c|c|c|c|c|c|c|}
\hline Author & Total citations & $1994-2000$ citations & 2001-2007 citations & $\%$ 2001-2007 & $\%$ self-citation & McKercher (2008) \\
\hline Chris Ryan & 323 & 134 & 189 & $58.5 \%$ & $20.7 \%$ & 14 \\
\hline Colin Michael Hall & 200 & 85 & 115 & $57.5 \%$ & $6.0 \%$ & 3 \\
\hline Philip Pearce & 198 & 121 & 77 & $38.9 \%$ & $9.6 \%$ & 7 \\
\hline Erik Cohen & 175 & 89 & 86 & $49.1 \%$ & - & 4 \\
\hline Abraham Pizam & 133 & 49 & 84 & $63.2 \%$ & $3.0 \%$ & 9 \\
\hline Stephen Page & 123 & 37 & 86 & $69.9 \%$ & $26.8 \%$ & 23 \\
\hline Richard Butler & 119 & 50 & 69 & $58.0 \%$ & - & 5 \\
\hline Jeff Wilks & 107 & 58 & 49 & $45.8 \%$ & $19.6 \%$ & - \\
\hline Douglas Pearce & 104 & 58 & 46 & $44.2 \%$ & $30.8 \%$ & 10 \\
\hline Don Getz & 83 & 36 & 47 & $56.6 \%$ & $3.6 \%$ & 13 \\
\hline John Urry & 81 & 36 & 45 & $55.6 \%$ & - & 2 \\
\hline Dean MacCannell & 79 & 37 & 42 & $53.2 \%$ & - & 6 \\
\hline Bill Faulkner & 77 & 19 & 58 & $75.3 \%$ & $19.5 \%$ & - \\
\hline Gianna Moscardo & 68 & 30 & 38 & $55.9 \%$ & - & 55 \\
\hline John Crompton & 62 & 29 & 33 & $53.2 \%$ & - & 1 \\
\hline Larry Dwyer & 61 & 19 & 42 & $68.9 \%$ & $27.9 \%$ & 48 \\
\hline Peter Murphy & 59 & 33 & 26 & $44.1 \%$ & $6.8 \%$ & - \\
\hline Greg Ashworth & 58 & 29 & 29 & $50.0 \%$ & - & 15 \\
\hline Graham Dann & 58 & 26 & 32 & $55.2 \%$ & - & 18 \\
\hline Neil Leiper & 56 & 38 & 18 & $32.1 \%$ & $3.6 \%$ & - \\
\hline Bruce Prideaux & 56 & 9 & 47 & $83.9 \%$ & $30.4 \%$ & - \\
\hline Valene Smith & 53 & 25 & 28 & $52.8 \%$ & - & 34 \\
\hline Martin Oppermann & 52 & 24 & 28 & $53.8 \%$ & $19.2 \%$ & 22 \\
\hline Mark Orams & 51 & 17 & 34 & $66.7 \%$ & $19.6 \%$ & - \\
\hline Yvette Reisinger & 49 & 9 & 40 & $81.6 \%$ & $8.2 \%$ & - \\
\hline
\end{tabular}


Pizam. Authors who have been cited considerably less by other Australians and New Zealanders writing in Annals and Tourism Management over the last 7 years include Neil Leiper, Phil Pearce, Doug Pearce, Jeff Wilks and Peter Murphy.

The table also indicates the extent of self-citation. Selfcitation instances are calculated only where an author has cited a paper for which they are the lead author. The selfcitation rates for international authors will be skewed by the fact that this sample only includes articles that they have co-authored with Australians and New Zealanders. Although some bibliometric studies exclude self-citations, they have been retained in these data. There are a number of legitimate reasons for self-citation. In niche areas of research authors may have no choice in citing themselves, while self-citations in co-authored papers may actually be the result of a co-author citing one of their collaborators. In addition, self-citation of previously published work is considered good ethical practice and reduces the likelihood of self-plagiarism.

While the analysis of most-cited authors is useful, it is arguably more interesting to explore the most-cited individual works. Table 7 provides a list of articles that were cited 10 or more times by Australian and New Zealand researchers.

Only 25 works were cited 10 or more times by the sample of Australian and New Zealand papers. Eighty-six per cent were cited only once and $99 \%$ were cited less than five times. Experienced tourism researchers will not be surprised by many of the works on this list, but it does provide new researchers and those from outside the region with a good indication of the sources that are influencing Australian and New Zealand researchers. One immediate observation is that the most cited works in tourism include both books and journals. Annals has been particularly influential in this regard. It is noteworthy that seven of these works were published between 1975 and 1979 , a period which has been associated with the emergence of the field (Graburn \& Jafari, 1991). The influence of several authors is amplified by the fact that their works appear more than once on the list. These authors include Erik Cohen, John Urry, Dean MacCannell, Phil Pearce and the more recent work of Stephen Page. The works represent several disciplinary perspectives, including geography, sociology, psychology and anthropology.

It is possible to review the frequency of citations over time, and Figure 3 provides a summary of this information for the 25 most-cited works. In total, these works are cited 384 times between 1994 and 2007. A noteworthy point is the relative stability of citations for the most frequently cited papers in terms of their continuing appearance in the citation rankings. While some works have clearly been cited less over the most recent 7-year period, all works continue to be influential. These works might therefore be regarded as 'classics' in the tourism field (at least by Australian and New Zealand researchers).

Table 7

Most Cited Works in Annals and Tourism Management, 1994-2007

\begin{tabular}{|c|c|c|c|c|}
\hline Author & Title & Publication source & Citations & Citations/Year \\
\hline Butler (1980) & $\begin{array}{l}\text { Concept of a Tourist Area Cycle of Evolution: Implications for Management } \\
\text { of Resources }\end{array}$ & Canadian Geographer & 34 & 2.4 \\
\hline Urry (1990) & The Tourist Gaze: Leisure and Travel in Contemporary Societies & Book & 30 & 2.1 \\
\hline MacCannell (1976) & The Tourist: A New Theory of the Leisure Class & Book & 28 & 2.0 \\
\hline Smith (1977) & Hosts and Guests: An Anthropology of Tourism & Edited volume & 22 & 1.6 \\
\hline Pearce P.L. (1982) & The Social Psychology of Tourist Behavior & Book & 19 & 1.4 \\
\hline Mathieson \& Wall (1982) & Tourism: Economic, Physical and Social Impacts & Book & 17 & 1.2 \\
\hline Ryan (1991) & Recreational Tourism: A Social Science Perspective & Book & 17 & 1.2 \\
\hline Cohen (1988) & Authenticity and Commoditization in Tourism & Annals of Tourism Res. & 16 & 1.1 \\
\hline Crompton (1979) & Motivations for Pleasure Vacation & Annals of Tourism Res. & 15 & 1.1 \\
\hline Pearce P.L. (1988) & The Ulysses Factor: Evaluating Visitors in Tourist Settings & Book & 15 & 1.1 \\
\hline Murphy (1985) & Tourism. A Community Approach & Book & 14 & 1.0 \\
\hline Cohen (1972) & Toward a Sociology of International Tourism & Social Research & 13 & 0.9 \\
\hline Cohen (1979b) & Rethinking the Sociology of Tourism & Annals of Tourism Res. & 12 & 0.9 \\
\hline Krippendorf (1987) & The Holidaymakers: Understanding the Impact of Leisure and Travel & Book & 12 & 0.9 \\
\hline Pizam (1978) & $\begin{array}{l}\text { Tourism's impacts: The Social Costs to the Destination Community } \\
\text { as Perceived by its Residents }\end{array}$ & Journal of Travel Res. & 12 & 0.9 \\
\hline Silver (1993) & Marketing Authenticity in Third World Countries & Annals of Tourism Res. & 12 & 0.9 \\
\hline Clift \& Page (1996) & Health and the International Tourist & Edited volume & 11 & 0.9 \\
\hline Cohen (1979a) & A Phenomenology of Tourist Experiences & Sociology & 11 & 0.8 \\
\hline MacCannell (1973) & Staged Authenticity: Arrangements of Social Space in Tourist Settings & American J. of Sociology & 11 & 0.8 \\
\hline Page \& Meyer (1996) & Tourist Accidents: An Exploratory Analysis & Annals of Tourism Res. & 11 & 0.9 \\
\hline Pearce D. (1989) & Tourist Development & Book & 11 & 0.8 \\
\hline Yiannakis \& Gibson (1992) & Roles tourists play & Annals of Tourism Res. & 11 & 0.8 \\
\hline Gunn (1979) & Tourism Planning & Book & 10 & 0.7 \\
\hline Turner \& Ash (1975) & The Golden Hordes: International Tourism and the Pleasure Periphery & Book & 10 & 0.7 \\
\hline Urry (1995) & Consuming Places & Book & 10 & 0.8 \\
\hline
\end{tabular}




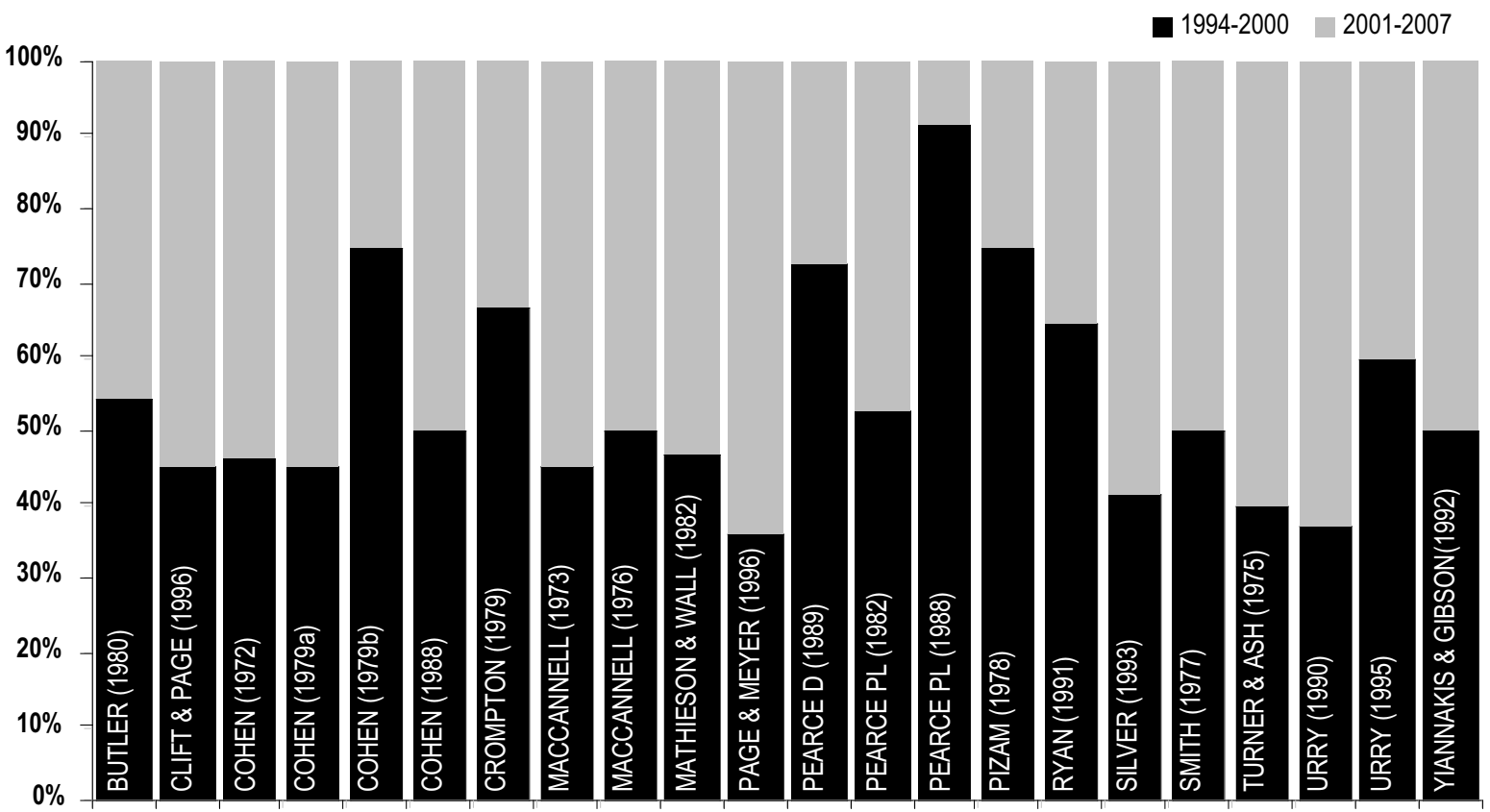

Figure 3

Frequency of citations, 1994-2000 and 2001-2007.

According to Price (1965), classics are works which are cited frequently over a sustained period of time by peers in the scholarly community.

Citation analysis is generally not a useful method for identifying emerging scholars and works. The only potential emerging work identified from an analysis of citations per year for all citations in the sample was Hall's (2005) work, Tourism: Rethinking the Social Science of Mobility. If this book continues to be cited at its current rate it has the potential to become a classic work.

The citation information can be used to conduct a cocitation analysis to better understand the relationships between the most cited works. The co-citation analysis identifies pairs of works that are frequently cited together in the same paper. From this information it is possible to construct a co-citation matrix of the works included in Table 6. Using this matrix, it is then possible to construct a network of influential tourism works using social network analysis. Figure 4 shows the pattern of citations for the most influential articles. This network provides a diagrammatical representation of the relative distances between works, and illustrates structural patterns and differing positions within the network.

The figure shows only those links with three or more cocitations in order to keep the diagram relatively uncluttered and easier to interpret. The thickness of the links represents the strength of co-citation ties, while the size of each node indicates the number of citations for each work.

A common network analysis technique involves examining core and peripheral nodes to contrast the central players from those who have only limited connections with their peers. The core represents the central themes of the literature, whereas the periphery is concerned with emerg- ing subfields. It is also useful to identify clusters of related nodes within the network. A number of research clusters are evident from the network in Figure 5. There are three substantial nodes that link to other works. Butler's (1980) seminal work in applying the product lifecycle to destinations has been the most influential and forms an important hub. This is at least partly due to the intuitive nature of his destination lifecycle model, and partly because the model can be linked with a variety of topics including social, environmental and economic impacts, sustainability, demand and visitor characteristics such as motivation and satisfaction. These links are evident in the network but there is a clear clustering of works dealing with development, planning, community and tourism impacts towards the lower part of the network.

A second more prominent cluster revolves around the work of MacCannell (1976) and Smith (1977) and Urry's (1990) more recent work on the Tourist Gaze. MacCannell's work is frequently cited along with Urry's Tourist Gaze and Cohen's works on authenticity and the sociology of tourism. The postmodern emphasis of Urry's work and its attempt to present tourism as part of a broader pattern of social and economic interactions makes it widely applicable to a range of research topics. There is also a strong link to Silver's (1993) more recent work on authenticity. This suggests a collective body of sociology and anthropology work with a strong postmodern emphasis as a major cluster of influence for tourism researchers in Australia and New Zealand.

Connected with this cluster is a third, somewhat linear cluster of work that encompasses the works or Crompton (1979), Pearce (1982, 1988), and Yiannikis and Gibson (1992). This cluster is concerned with understanding and 


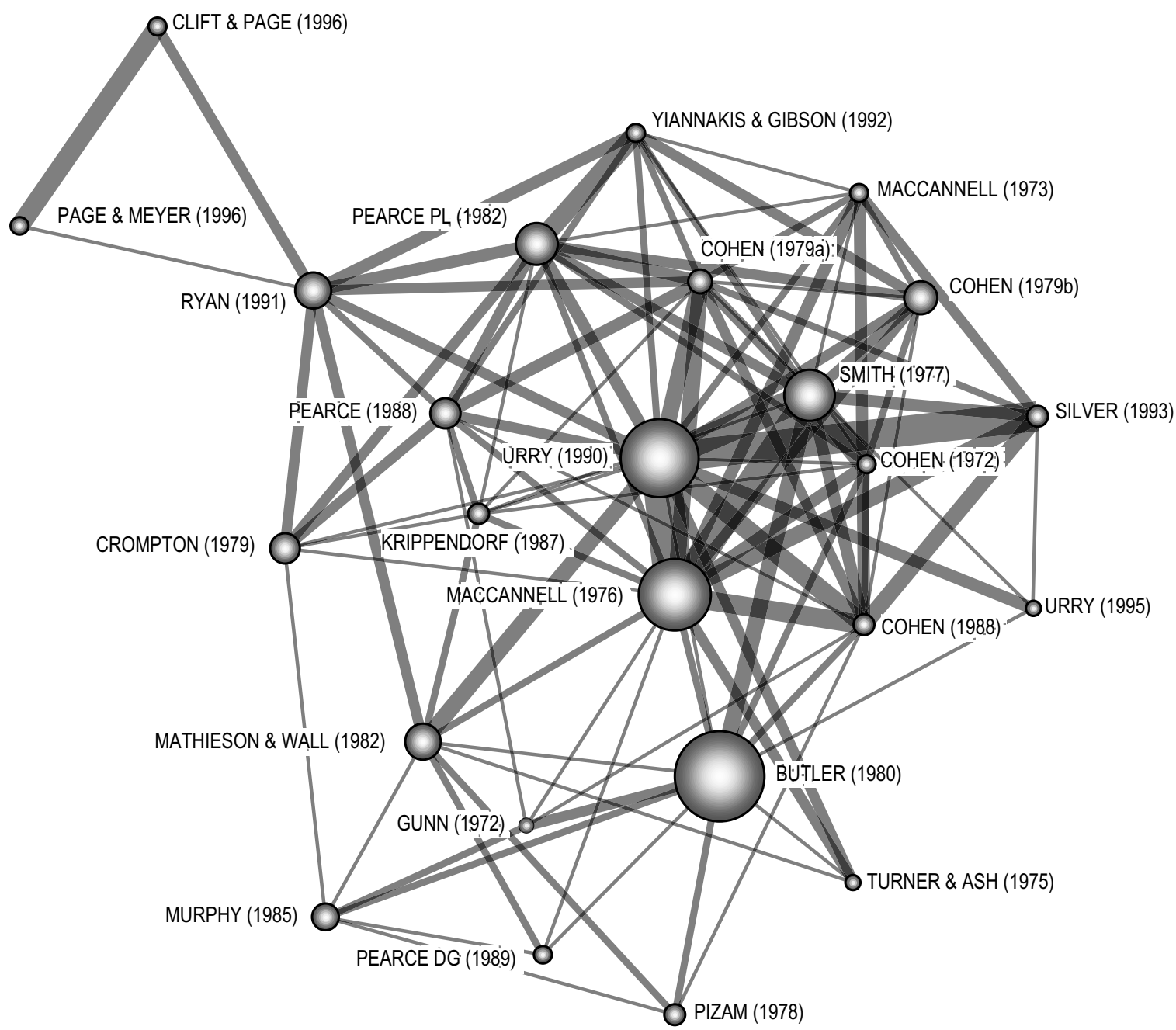

Figure 4

Co-citation/network analysis of most influential works.

measuring tourist behaviour. Ryan's (1991) Recreational Tourism draws on all of these clusters in an attempt to offer an 'all in one' comprehensive coverage of a range of topics in tourism. Linked to this work, on the periphery of the network are the two more recent works by Clift \& Page (1996) and Page \& Meyer (1996) dealing with tourist health and safety.

From a longitudinal perspective, the works that make up the first cluster (geography, development, development, impacts) and the third cluster (tourist behaviour) were cited less frequently between 2001 and 2007 than they were between 1994 and 2000.

\section{Discussion and Conclusions}

The purpose of this article is to provide a window through which the knowledge domain of Australian and New Zealand tourism research can be examined. The keyword, citation and co-citation analyses that have been presented make a number of useful contributions. A major contribution is the use of a network analysis technique to analyse the 11,629 citations in the 334 articles published by Australian and New Zealand researchers in Annals and Tourism Management between 1994 and 2007. This quantitative relational analysis adds to previous evaluative studies and qualitative review articles relying largely on the observations and reflections. The analysis has highlighted the most influential authors, works and journals and has identified a number of important links between influential works. The network analysis of keywords and co-citations indicates that tourism research in Australia and New Zealand is largely being driven by theories from sociology, anthropology, psychology and geography. An important finding that has emerged from this study is the influence of the sociology and anthropology literature in tourism. Researchers are also drawing on works authored by scholars in a number of countries, however scholars from the United States, the United Kingdom, Australia and New Zealand have been the most influential.

Many of the most influential works have been books or papers appearing in Annals, but the analysis suggests that Tourism Management may be growing in influence. Further 
research is needed to confirm this but it will be interesting to observe the evolving influence of particular journals.

Evident in the keyword analysis, and even more lucid in the co-citation analysis are several echoes of Jafari's (1990) platforms of tourism scholarship. The cautionary platform is particularly well represented through the works of Turner \& Ash, Smith, Pizam and Mathieson \& Wall and an interest in keywords such as 'conservation' and 'impacts'. There is also an element of the adaptancy platform through the work of Cohen and Krippendorf and a focus on keywords such as 'ecotourism' and 'sustainability' (although Macbeth (2005) argues that sustainable tourism is itself an additional platform). A knowledge-based platform perspective is particularly notable in the work of Ryan and in the use of keywords such as 'model' and 'systems'. The research in Australia and New Zealand, however, does not appear to extend to the strong positivist approaches evident in North America. It is clear that works representing the advocacy platform do not feature and are not highly influential. Furthermore, examining some of the trends and changes evident in this small dataset of Australian and New Zealand researchers one might conclude that there is a fifth platform not concerned so much with impacts, communities or destinations, but with the tourists themselves. This platform is concerned with tourist satisfaction, motives and experiences and extends to an interest in the wellbeing of tourists, as evidenced by the work of Clift \& Page and Page \& Meyer.

Some influential works from the areas of economics, management (e.g., Porter) or marketing and consumer research (e.g., Zeithaml, Parasuraman \& Berry; Bitner) might have been expected. The list of most frequently cited journals includes several marketing journals, but it appears that no single work has received a critical mass of citations. The body of work dealing with destination image has also been widely cited in recent times but while related themes appear in the keyword network, it appears no single work has attracted a critical mass of citations. This is perhaps because a number of key publications on this topic were published in the late 1990s and early 2000s.

Despite the contributions made, several limitations need to be noted. This study only focuses on articles that appeared in Annals and Tourism Management. Might the analysis reach different conclusions if other journals were included? Perhaps, but the analysis is based on over 11,000 citations. It is common for bibliometric studies of this nature to limit their analyses to a small number of leading and influential journals in a field. While Annals has traditionally taken a strong sociology/anthropology perspective, Tourism Management moderates this literature somewhat. The purpose of this paper was to identify the most influential literature used by Australian and New Zealand researchers and in this context it seems appropriate to examine source papers from the leading tourism journals. Future studies should consider including other relevant general tourism journals such as fournal of Travel Research. Given the time lag associated with publishing journal articles, future research might include papers from leading conferences in an attempt to provide a more accu- rate forecast about emerging trends. However, capturing these data would be costly and time consuming.

Further analysis might include co-author analysis, to examine the collaborative networks between tourism scholars. An analysis of the location of authors could be extended to examine the geographical or organisational distance between co-authors. Cross-institutional collaborations could also be explored. Such information may show the level of international collaborations and flow of knowledge between different institutions and countries. Furthermore, researchers from different regions may have very different research emphases, and such differences would also be worthy of further exploration.

\section{References}

Acedo, F.J., Barroso, C., \& Galan, J.L. (2006). The resource-based theory: Dissemination and main trends. Strategic Management fournal, 27(7), 621-636.

Acedo, F.J., \& Casillas, J.C. (2005). Current paradigms in the international management field: An author co-citation analysis. International Business Review, 14(5), 619-639.

Australian Business Deans Council. (2008). Abdc journals list. Retrieved 29 August 2008, from http://www.abdc.edu.au/

Baloglu, S., \& Assante, L.M. (1999). A content analysis of subject areas and research methods used in five hospitality management journals. Fournal of Hospitality \& Tourism Research, 23(1), 53-70.

Barrios, M., Borrego, A., Vilagines, A., Olle, C., \& Somoza, M. (2008). A bibliometric study of psychological research on tourism. Scientometrics, $1-15$.

Beed, C., \& Beed, C. (1996). Measuring the quality of academic journals: The case of economics. Fournal of Post Keynesian Economics, 18(3), 369-389.

Borgatti, S.P., Everett, M.G., \& Freeman, L.C. (2008). Ucinet version 6. Natick: Analytic Technologies.

Borgman, C.L., \& Furner, J. (2002). Scholarly communication and bibliometrics. Annual Review of Information Science and Technology, 36, 3-72.

Brey, E.T., Morrison, A.M., \& Mills, J.E. (2007). An examination of destination resort research. Current Issues in Tourism, 10(5), 415-442.

Butler, R.W. (1980). The concept of a tourist area cycle of evolution: Implications for management of resources. The Canadian Geographer, 24(1), 5-12.

Casillas, J., \& Acedo, F. (2007). Evolution of the intellectual structure of family business literature: A bibliometric study of fbr. Family Business Review, 20(2), 141-162.

Clift, S., \& Page, S. (1996). Health and the international tourist. London: Routledge.

Cohen, E. (1972). Towards a sociology of international tourism. Social Research, 39, 164-182.

Cohen, E. (1979a). A phenomenology of tourist experiences. Sociology, 13(2), 179.

Cohen, E. (1979b). Rethinking the sociology of tourism. Annals of Tourism Research, 6(1), 18-35.

Cohen, E. (1988). Authenticity and commoditization in tourism. Annals of Tourism Research, 15(3), 371-386.

Crawford-Welch, S., \& Mccleary, K.W. (1992). An identification of the subject areas and research techniques used in five hospitality-related journals. International fournal of Hospitality Management, 11(2), 155-167.

Crompton, J.L. (1979). Motivations for pleasure vacation. Annals of Tourism Research, 6(4), 408-424.

Dann, G., Nash, D., \& Pearce, P. (1988). Methodology in tourism research. Annals of Tourism Research, 15, 1-28.

Egghe, L. (2006). Theory and practice of the g index. Scientometrics, 69(1), 131-152. 
Ferreira, R.R., Defranco, A.L., \& Rappole, C.L. (1994). Rating the hospitality journals. International fournal of Hospitality Management, 13(3), 209-218.

Ferreira, R.R., Defranco, A.L., \& Rappole, C.L. (1998). Hospitality program directors' rating on hospitality journals. Fournal of Hospitality and Tourism Education, 10(1), 46-52.

Graburn, N.H. H., \& Jafari, J. (1991). Introduction: Tourism social science. Annals of Tourism Research, 18(1), 1-11.

Gunn, C. (1979). Tourism planning. New York: Rusak.

Hall, C.M. (2005). Systems of surveillance and control: Commentary on 'an analysis of institutional contributors to three major academic tourism journals: 1992-2001'. Tourism Management, 26(5), 653-656.

Hall, C.M. (2005). Tourism: Rethinking the social science of mobility: Harlow: Pearson Education.

Hirsch, J.E. (2005). An index to quantify an individual's scientific research output. Proceedings of the National Academy of Science. 4. Retrieved August 29, 2008, from http://www.pnas.org/content/102/46/16569. full.pdf+html

Hollinshead, K. (1991). Scientific nature of anthropology. Annals of Tourism Research, 18(4), 653-658.

Howey, R.M., Savage, K.S., Verbeeten, M.J., \& Van Hoof, H.B. (1999). Tourism and hospitality research journals: Cross-citations among research communities. Tourism Management, 20(1), 133-139.

Hsu, C.H. C., \& Yeung, M. (2003). Perceived ranking of hospitality and tourism journals and school. Paper presented at the First APACCHRIE Conference.

$\mathrm{Hu}, \mathrm{C}$., \& Racherla, P. (2008). Visual representation of knowledge networks: A social network analysis of hospitality research domain. International fournal of Hospitality Management, 27(2), 302-312.

Jafari, J. (1990). Research and scholarship: The basis of tourism education. Fournal of Tourism Studies, 1(1), 33-41.

Jamal, T., Smith, B., \& Watson, E. (2008). Ranking, rating and scoring of tourism journals: Interdisciplinary challenges and innovations. Tourism Management, 29(1), 66-78.

Jogaratnam, G., Chon, K., McCleary, K., Mena, M., \& Yoo, J. (2005). An analysis of institutional contributors to three major academic tourism journals: 1992-2001. Tourism Management, 26(5), 641-648.

Jogaratnam, G., McCleary, K.W., Mena, M.M., \& Yoo, J.J. (2005). An analysis of hospitality and tourism research: Institutional contributions. fournal of Hospitality \& Tourism Research, 29(3), 356-371.

Kim, J., \& McMillan, S.J. (2008). Evaluation of internet advertising research: A bibliometric analysis of citations from key sources. Fournal of Advertising, 37(1), 99.

Krippendorf, J. (1987). The holiday makers: Understanding the impact of leisure and travel. London: Heinemann.

Law, R., \& Chon, K. (2007). Evaluating research performance in tourism and hospitality: The perspective of university program heads. Tourism Management, 28(5), 1203-1211.

Leydesdorff, L. (1998). Theories of citation? Scientometrics, 43(1), 5-25.

Losekoot, E., Verginis, C.S., \& Wood, R.C. (2001). Out for the count: Some methodological questions in 'publications counting' literature. International fournal of Hospitality Management, 20(3), 233-244.

Macbeth, J. (2005). Towards an ethics platform for tourism. Annals of Tourism Research, 32(4), 962-984.

Maccannell, D. (1973). Staged authenticity: Arrangements of social space in tourist settings. American fournal of Sociology, 79(3), 589-603.

Maccannell, D. (1976). The tourist: A new theory of the leisure class. New York: Schocken.

Mathieson, A., \& Wall, G. (1982). Tourism: Economic, physical, and social impacts. London: Longman Scientific \& Technical.

McKercher, B. (2005). A case for ranking tourism journals. Tourism Management, 26(5), 649-651.

McKercher, B. (2007). An analysis of prolific authors. Fournal of Hospitality and Tourism Education, 19(2), 23-30.

McKercher, B. (2008). A citation analysis of tourism scholars. Tourism Management, 29(6), 1226-1232.
McKercher, B., Law, R., \& Lam, T. (2006). Rating tourism and hospitality journals. Tourism Management, 27(6), 1235-1252.

Murphy, P.E. (1985). Tourism: A community approach. New York: Methuen.

Neely, A., Gregory, M., \& Platts, K. (2005). Performance measurement system design: A literature review and research agenda. International Fournal of Operations \& Production Management, 25(12), 1228.

Page, S.J. (2003). Evaluating research performance in tourism: The UK experience. Tourism Management, 24(6), 607-622.

Page, S.J. (2005). Academic ranking exercises: So they achieve anything meaningful? A personal view. Tourism Management, 26(5), 663-666.

Page, S.J., \& Meyer, D. (1996). Tourist accidents: An exploratory analysis. Annals of Tourism Research, 23(3), 666-690.

Palmer, A.L., Sesé, A., \& Montaño, J.J. (2005). Tourism and statistics: Bibliometric study 1998-2002. Annals of Tourism Research, 32(1), 167-178.

Park, Y.A., \& Gretzel, U. (2007). Success factors for destination marketing sites: A qualitative meta-analysis. Fournal of Travel Research, 46(1), 46-63.

Pasadeos, Y., Phelps, J., \& Kim, B.-H. (1998). Disciplinary impact of advertising scholars: Temporal comparisons of influential authors, works and research networks. fournal of Advertising, 27(4), 53-70.

Pearce, D. (1989). Tourist development. Essex, England: Longman.

Pearce, D.G. (1992). A response from the periphery on authorship analysis. Annals of Tourism Research, 19(2), 347-349.

Pearce, P.L. (1982). The social psychology of tourist behavior. Oxford: Pergamon.

Pearce, P.L. (1988). The Ulysses factor: Evaluating visitors in tourist settings. New York: Springer Verlag.

Pechlaner, H., Zehrer, A., Matzler, K., \& Abfalter, D. (2004). A ranking of international tourism and hospitality journals. Fournal of Travel Research, 42(4), 328-332.

Pilkington, A., \& Chai, K.-H. (2008). Research themes, concepts and relationships. International fournal of Service Industry Management, 19(1), 83.

Pilkington, A., \& Fitzgerald, R. (2006). Operations management themes, concepts and relationships: A forward retrospective of IJOPM. International fournal of Operations E Production Management, 26(11), 1255.

Pizam, A. (1978). Tourism's impacts: The social costs to the destination community as perceived by its residents. Fournal of Travel Research, 16(4), 8 .

Price, D. (1965). Networks of scientific papers. Science, 149, 510-515.

Reid, L.J., \& Andereck, K.L. (1989). Statistical analyses use in tourism research. Fournal of Travel Research, 28, 21-24.

Ryan, C. (1991). Recreational tourism: A social science perspective. London: Routledge.

Ryan, C. (2005). The ranking and rating of academics and journals in tourism research. Tourism Management, 26(5), 657-662.

Samdahl, D.M., \& Kelly, J.J. (1999). Speaking only to ourselves? Citation analysis of journal of leisure research and leisure sciences. Fournal of Leisure Research, 31, 171-180.

Schildt, H.A., \& Mattsson, J.T. (2006). A dense network sub-grouping algorithm for co-citation analysis and its implementation in the software tool sitkis. Scientometrics, 67(1), 143-163.

Schmidgall, R., Woods, R.H., \& Hardigree, C. (2007). Hospitality's most influential scholars: Fifteen years of citation analyses (1989-2004). fournal of Hospitality and Tourism Education, 19(2), 32-43.

Shelby, L.B., \& Vaske, J.J. (2008). Understanding meta-analysis: A review of the methodological literature. Leisure Sciences, 30(2), 96-110.

Sheldon, P.J. (1990). Journal usage in tourism: Perceptions of publishing faculty. Fournal of Tourism Studies, 1(1), 42-48.

Sheldon, P.J. (1991). An authorship analysis of tourism research. Annals of Tourism Research, 18(3), 473-484.

Silver, I. (1993). Marketing authenticity in third world countries. Annals of Tourism Research, 20, 302-302. 
Smith, V.L. (1977). Hosts and guests: The anthropology of tourism. Philadelpia: University of Pennsylvania Press.

Swain, M.B., Brent, M., \& Long, V.H. (1999). Annals and tourism evolving indexing 25 years of publication. Annals of Tourism Research, 25(INDEX 1), 991-1014.

Thelwall, M. (2008). Bibliometrics to webometrics. Fournal of Information Science, 34(4), 605-621.

Turner, L., \& Ash, J. (1975). The golden hordes: International tourism and the pleasure periphery. London: Constable.

Urry, J. (1990). The tourist gaze: Leisure and travel in contemporary societies. London: Sage.

Urry, J. (1995). Consuming places. London: Routledge.

Weber, K., \& Ladkin, A. (2008). Career advancement for tourism and hospitality academics: Publish, network, study, and plan. Fournal of Hospitality $\mathcal{E}$ Tourism Research, 32(4), 448-466.

Wood, R.C. (1995). Assessing publications output as an indicator of academic productivity: The case of hospitality management. Tourism Management, 16(3), 171-173.
Xiao, H., \& Smith, S.L.J. (2005). Source knowledge for tourism research. Annals of Tourism Research, 32(1), 272-275.

Xiao, H., \& Smith, S.L. J. (2006a). The making of tourism research Insights from a social sciences journal. Annals of Tourism Research, 33(2), 490-507.

Xiao, H., \& Smith, S.L. J. (2006b). The maturation of tourism research: Evidence from a content analysis. Tourism Analysis, 10, 335-348.

Xiao, H., \& Smith, S.L. J. (2008). Knowledge impact an appraisal of tourism scholarship. Annals of Tourism Research, 35(1), 62-83.

Yiannakis, A., \& Gibson, H. (1992). Roles tourists play. Annals of Tourism Research, 19(2), 287-303.

Zehrer, A. (2007). The justification of journal rankings: A pilot study. Scandinavian fournal of Hospitality and Tourism, 7(2), 139-156.

Zhao, W., \& Ritchie, J.R. B. (2007). An investigation of academic leadership in tourism research: 1985-2004. Tourism Management, 28(2), 476-490. 